\title{
Características espaciales y cambios recientes en las aldeas periurbanas de «La tribu de las hormigas» en Beijing: Los casos de estudio de Tangjialing y Shigezhuang*
}

\author{
Chaolin Gu \\ Mingjie Sheng \\ Universidad de Tsinghua. Escuela de Arquitectura \\ gucl@tsinghua.edu.cn

\section{Lingqian $\mathrm{Hu}$} \\ Universidad de Wisconsin-Milwaukee. Escuela de Arquitectura y Urbanismo \\ lingqian.hu@gmail.com
}

Recibido: septiembre de 2015

Aceptado: enero de 2017

\section{Resumen}

En relación con el proceso de urbanización de China, desde el año 2000, se ha prestado atención principalmente a dos grupos sociales. Uno está constituido por la segunda generación de trabajadores agrícolas migrantes y otro, por los graduados universitarios de bajos ingresos, conocido como "La tribu de las hormigas" ("The ant tribe»). En los últimos años, las condiciones de supervivencia en las megalópolis chinas de los segundos han empeorado. Por eso, como estrategia de supervivencia, muchos de ellos optan por residir en viviendas más asequibles, aunque de calidad inferior, en los pueblos o aldeas periurbanas y no en las ciudades, cada vez más caras y polarizadas. Este trabajo analiza las características espaciales y los cambios registrados en las aldeas periurbanas de «La tribu de las hormigas» de Tangjialing y Shigezhuang, en Beijing. En primer lugar, el artículo describe las características espaciales de los graduados de bajos ingresos que proceden principalmente de zonas rurales, tienen un nivel de educación alto y adoptan modos de vida urbanos. En segundo lugar, el artículo analiza los efectos socioespaciales y los cambios recientes surgidos a raíz de la reconstrucción de las aldeas periurbanas. A partir de estos análisis, se demostrará que los jóvenes titulados de bajos ingresos son desplazados hacia áreas periurbanas más pobres y alejadas, por el proceso de revalorización residencial de los suburbios.

Palabras clave: urbanización; China; graduados universitarios de bajos ingresos; aldeas periurbanas; "La tribu de las hormigas»

* Traducción realizada por María José Piñeira Mantiñán. 
Resum. Caracteristiques espacials i canvis recents als llogarets periurbans de "La tribu de les formigues" a Pequin: Els casos d'estudi de Tangjialing i Shigezhuang

Pel que fa al procés d'urbanització de la Xina, des de l'any 2000, hom ha parat esment principalment a dos grups socials. L'un és constituït per la segona generació de treballadors agrícoles migrants i l'altre, pels graduats universitaris d'ingressos baixos, conegut com «La tribu de les formigues» («The ant tribe»). Els darrers anys, les condicions de supervivència a les megalòpolis xineses dels segons han empitjorat. Per això, n’hi ha molts que opten per residir en habitatges més assequibles com a estratègia de supervivència, encara que de qualitat inferior, als pobles o llogarets periurbans i no a les ciutats, cada vegada més cares i polaritzades. Aquest treball analitza les característiques espacials i els canvis registrats als pobles periurbans de «La tribu de les formigues» de Tangjialing i Shigezhuang, a Pequín. En primer lloc, l'article descriu les característiques espacials dels graduats de baixos ingressos que procedeixen principalment de zones rurals, que tenen un nivell d'educació alt i que adopten estils de vida urbans. En segon lloc, l'article analitza els efectes socioespacials i els canvis recents esdevinguts arran de la reconstrucció dels pobles periurbans. A partir d'aquesta anàlisi, es demostrarà que els joves titulats de baixos ingressos són desplaçats cap a les àrees periurbanes més pobres i allunyades, a causa del procés de revalorització residencial dels suburbis.

Paraules clau: urbanització; Xina; graduats universitaris d'ingressos baixos; llogarets periurbans; «La tribu de les formigues»

Résumé. Caractéristiques spatiales et changements récents dans les villages périurbains de la "Tribu des Fourmis » à Pékin: étude des cas de Tangjialing et Shigezhuang

Depuis le processus d'urbanisation de la Chine, à partir de l'année 2000 l'attention a principalement porté sur deux groupes sociaux. L'un est constitué par la deuxième génération de travailleurs agricoles migrants, et l'autre par les diplômés universitaires de bas revenus, connus comme la tribu de fourmis (Ant Tribe). Lors de ces dernières années, les conditions de survie des récemment diplômés dans les mégapoles chinoises ont empiré. C'est pourquoi beaucoup d'entre eux choisissent, comme stratégie de survie de résider dans des logements plus abordables, bien que de qualité inférieure, dans les villages périurbains et non pas dans les villes, de plus en plus coûteuses et polarisées. Ce travail analyse les caractéristiques spatiales et les changements enregistrés dans les villages périurbains de la tribu des fourmis de Tangjialing et Shigezhuang, à Pékin. En premier lieu, l'article décrit les caractéristiques spatiales des diplômés de bas revenus qui proviennent principalement de zones rurales, avec un niveau d'éducation élevé et adoptant des modes de vie urbains. Deuxièmement, l'article analyse les effets socio-spatiaux et les changements récents surgis à la suite de la reconstruction des villages périurbains. Enfin, nous constatons que les diplômés universitaires récents sont déplacés vers les quartiers les plus pauvres et les plus éloignés, en raison de la revalorisation des banlieues intérieures.

Mots-clés: urbanisation; Chine; diplômés universitaires de bas revenus; villages périurbains; tribu des fourmis

Abstract. Spatial characteristics and new changes of the "ant tribe" urban villages in Beijing: Case studies of Tangjialing and Shigezhuang

Since the year 2000, and in relation with China's urbanization process, many politicians and scholars have paid attention to two social groups: the second generation of migrant farm workers and low-income college graduates known as the "ant tribe". In recent years, 
the survival conditions of new college graduates in Chinese mega-cities have worsened. A large number of them opt for affordable yet substandard housing in urban villages as a survival strategy in increasingly commercialized and polarized cities. This paper analyzes the spatial characteristics and new changes of the urban village "ant tribe" in Tangjialing and Shigezhuang, Beijing. Firstly, the case study describes the spatial characteristics of these low-income graduates who are mainly from the countryside, have a high educational level and embrace city lives. Secondly, the socio-spatial effects and new changes after the reconstruction of the urban village are examined. It is found that recent college graduates are being displaced to the poorest and most remote suburban areas due to the revalorization of the inner suburbs.

Keywords: urbanization; China; low-income college graduates; urban villages; ant tribe

\section{Sumario}

1. Introducción 5. Nuevos cambios en los asentamientos

2. Un caso de estudio: Tangjialing

3. Características espaciales del asentamiento de «La tribu de las hormigas"

4. Efectos socioespaciales de "La tribu de las hormigas"

6. Conclusiones

Agradecimientos

Referencias bibliográficas

de la reurbanización en el asentamiento de «La tribu de las hormigas»

\section{Introducción}

Las aldeas periurbanas son un fenómeno común de asentamientos de inmigrantes en el entorno de la ciudad. La investigación sobre las aldeas (peri) urbanas puede remontarse a Herbert Gans (1962), quien utiliza dicho término para describir los lugares donde se establecen los asentamientos principales o secundarios de migrantes urbanos que «tratan de adaptar sus instituciones y culturas no urbanas al mundo urbano». Dicho autor identificó cuatro aspectos principales que definen estas aldeas (peri)urbanas (Gans, 1962: 17-41):

1. El lugar y los patrones de residencia.

2. La clase y las divisiones de clase.

3. La cultura y la etnia (incluyendo la gastronomía, la lengua, la estructura del hogar, el grado de integración y la religión).

4. La estructura social.

La mayoría de los países occidentales experimentaron una rápida urbanización hasta la década de 1970, momento en el que el nivel de urbanización se sitúa en torno a un $70 \%$. Desde entonces, el proceso de urbanización en los países occidentales se ha ralentizado y algunas ciudades han experimentado una contraurbanización. Así, la noción convencional de Gans para las aldeas (peri) 
urbanas parece que no puede aplicarse en el caso de los países occidentales, pues el concepto contemporáneo de aldea (peri)urbana difiere del de Gans en que adopta un punto de vista más nostálgico de escala humana, del uso mixto y de los lugares bien diseñados (Franklin y Tait, 2002).

En China, sin embargo, todavía se aplica el concepto de aldea (peri)urbana y el marco de investigación de Gans, aunque el contexto y la naturaleza de los pueblos urbanos hayan cambiado (Chung, 2010). Las aldeas periurbanas de China son asentamientos en tierras que eran originalmente rurales, pero que progresivamente fueron incorporadas a las jurisdicciones metropolitanas como consecuencia del proceso de urbanización. No obstante, dichas aldeas se encuentran separadas de la zona urbana circundante. Están emplazadas en una franja definida por construcciones no autorizadas, un ambiente insalubre, altos índices de criminalidad e infraestructuras insuficientes. En estas aldeas periurbanas, conviven pobladores autóctonos con algunos inmigrantes. Estos últimos no suelen tener dinero suficiente para residir en otras partes de la ciudad y, en su mayoría, son originariamente agricultores procedentes de las áreas rurales de China.

Después de la entrada de China en la Organización Mundial del Comercio (OMC) en 2001, su despegue como «Fábrica del mundo» requirió una fuerza de trabajo cada vez mayor en la industria secundaria, que, en su mayoría, estuvo compuesta por el excedente de mano de obra rural. Más de 230 millones de campesinos abandonaron sus fincas y se trasladaron a las ciudades como trabajadores migrantes (National Bureau of Statistics of China, 2012). Muchos de ellos continúan siendo pobres y aumentan la polarización en las ciudades (Sit, 2000; Gu y Liu, 2001; Logan, 2001; Gu y Kesteloot, 2002; Chen et al., 2004). Investigadores chinos y del extranjero han estudiado la pobreza urbana en relación con la transición socioespacial surgida a raíz del proceso de urbanización (Gaubatz, 1995; Gu y Kesteloot, 1997; Ma y Xiang, 1998; Xiang, 1999; Gu y Shen, 2003; Feng, 2004; Gu et al., 2005; Chen et al., 2006; Liu y Wu, 2006; Gu et al., 2006; Feng et al., 2008; Yuan et al., 2009; Gu et al., 2010). Se presta especial atención a los trabajadores migrantes, a su formación y características. En general, suelen tener bajo nivel educativo (Liang et al., 2002) y trabajan en la industria manufacturera, la construcción y el sector servicios (Chen y Coulson, 2002). Se encuentran en una situación de desamparo en las ciudades, tienen dificultades para adaptarse a la vida urbana y continúan siendo un colectivo marginado en las mismas (Wong et al., 2007).

En los últimos años, el creciente número de migrantes que viven en aldeas periurbanas se ha diversificado. Entre ellos, sobresalen dos grupos sociales que desde el año 2000 están acaparando la atención de los políticos y académicos. Uno es la segunda generación de los trabajadores migrantes, el otro es el correspondiente a los graduados universitarios de bajos ingresos (que conforman una nueva generación de recién asentados). Esta investigación se centrará en el segundo grupo, conocido como "La tribu de las hormigas", con el objetivo de comprender su formación, su distribución espacial y sus características sociales. El fenómeno «tribu de las hormigas» llama la atención no solo del público en 
general, sino también de los responsables políticos e investigadores (Lian, 2009, 2010a, 2010b). En los últimos años, incluso hay un programa de televisión muy popular llamado La lucha de la tribu de las hormigas, en el que se refleja la vida de los graduados universitarios de bajos ingresos. No obstante, a pesar de que el incremento de graduados universitarios de bajos ingresos en las aldeas periurbanas se ha convertido en un fenómeno nuevo, los estudios académicos que se han llevado a cabo sobre dicho colectivo social son muy recientes y en parte incompletos, al igual que las soluciones políticas sugeridas para tratar al colectivo (He et al., 2011; Gu y Sheng, 2012; Gu et al., 2013).

A pesar de que una amplia investigación ha arrojado luz sobre el fenómeno de "La tribu de las hormigas», su mecanismo y sus implicaciones socioespaciales siguen sin conocerse bien. Con este artículo, nos acercaremos a las características socioespaciales de "La tribu de las hormigas» en Beijing. Para esto, hemos recurrido al trabajo de campo y a la aplicación de técnicas de sondeo tales como la observación no participante, entrevistas y cuestionarios como método de muestreo de bola de nieve en Tangjialing durante marzo de 2009, octubre de 2011, noviembre de 2012 y agosto de 2013. Partiendo del análisis de datos primarios, el artículo también trata de comprender el lugar y la cultura del área del caso de estudio.

\section{Un caso de estudio: Tangjialing}

Tangjialing está compuesto por las aldeas de Tangjialing y Dengzhuang, ambas limítrofes con el distrito de Haidian en las afueras del Quinto Anillo del norte de Beijing (figura 1). Tangjialing dista siete kilómetros del Parque Científico y Tecnológico de Zhongguancun y tiene una superficie total de 394 hectáreas. Solo hay 1.760 residentes locales, de los cuales 250 son pobladores rurales. Sin embargo, encontramos cerca de 50.000 migrantes, la mayoría de ellos nuevos graduados con bajos ingresos. En 2009, dicha área contaba aproximadamente con 3.000 unidades para alquilar.

Antes del año 2000, Tangjialing fue un asentamiento rural típico de los suburbios de Beijing, que se transformó rápidamente con el surgimiento de la industria de la tecnología de la información, a raíz de la puesta en marcha del Parque Científico y Tecnológico de Zhongguancun, del Centro de Industria Software Shangdie, y de la Ciudad Aeroespacial de Beijing (figura 2). El auge de las industrias de tecnología de la información sentó las bases para crear un centro privado de formación, el Instituto de Gestión de Software, cuyos estudiantes se convirtieron en el primer grupo de inquilinos de Tangjialing. Con el derribo de los pueblos cercanos de Shu y Malianwa, Tangjialing se convirtió en el único pueblo urbano en las proximidades de Zhongguancun y Shangdi. Pero fue a partir de 2003 cuando se registró el mayor crecimiento de Tangjialing (figura 3). A medida que llegaban más graduados universitarios que querían alquilar, los aldeanos comenzaron a reconstruir sus viviendas de una sola planta hasta convertirlas en edificios de tres o cuatro pisos, para así poder obtener más beneficios. A pesar de que dichas reconstrucciones 
Figura 1. Localización de la villa de Tangjialing, en Beijing

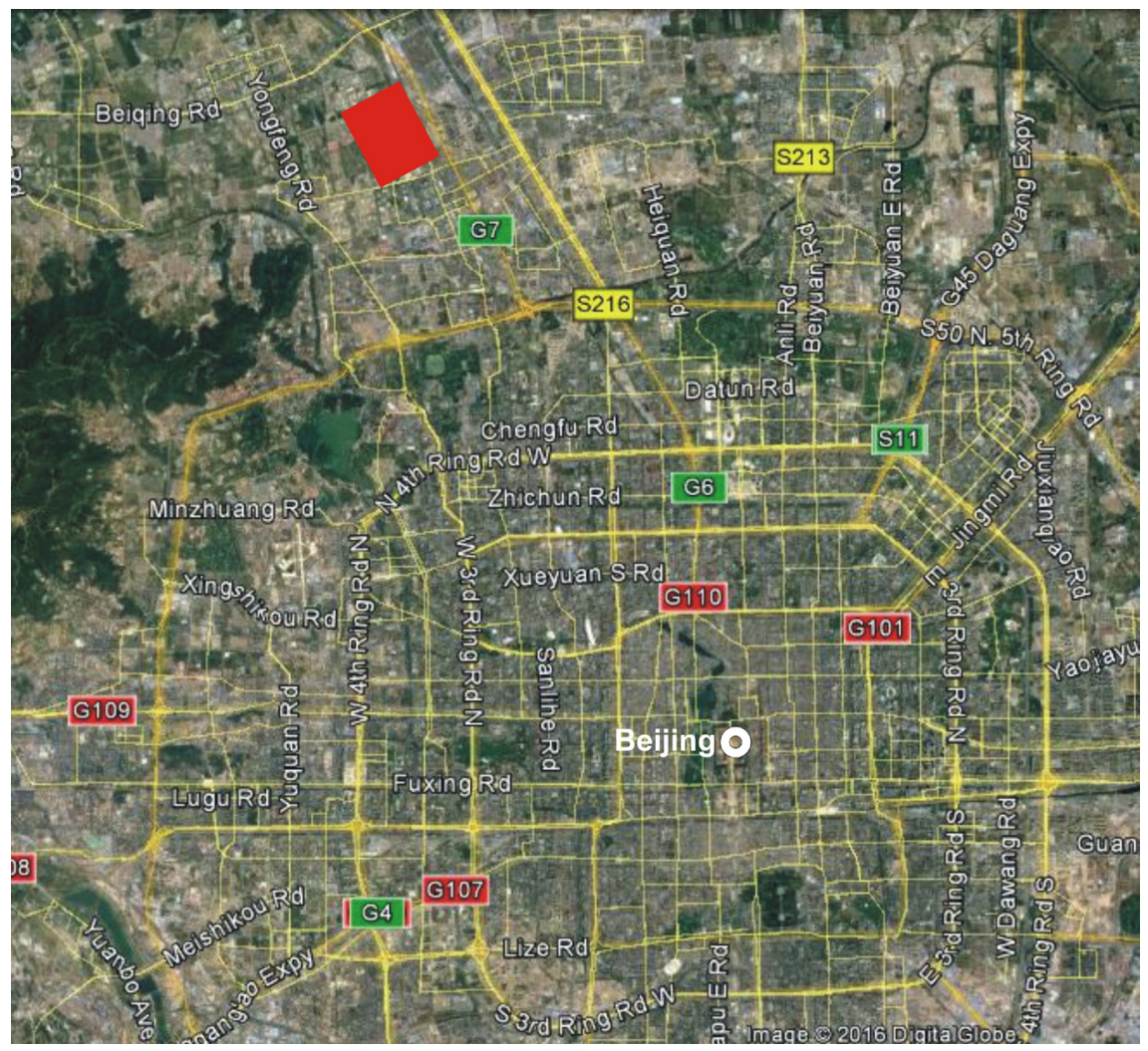

Fuente: Satélite Gaofen-3.

eran ilegales, la actividad no se detuvo hasta 2010, cuando la aldea urbana fue desplazada.

\section{Características espaciales del asentamiento de «La tribu de las hormigas»}

\subsection{El espacio habitable}

\subsubsection{Las calles}

En Tangjialing, hay tres calles principales alineadas norte-sur, altamente congestionadas, pero llenas de actividad. La calle principal es Tangjialing Middle Street, que es la principal vía de acceso al tráfico rodado y el eje comercial más importante. A ambos lados de la misma, se pueden encontrar tiendas de comestibles, música, puestos de bocadillos y de frutas en las aceras, así como todo tipo de restaurantes, como el Dongbei, el Sichuan, el Hunan y el MaLaTang. Los callejones y las pequeñas carreteras de la aldea no facilitan el acceso 
Figura 2. Área del caso de estudio. Localización de la aldea periurbana de Tangjialing y el Centro Shangdi

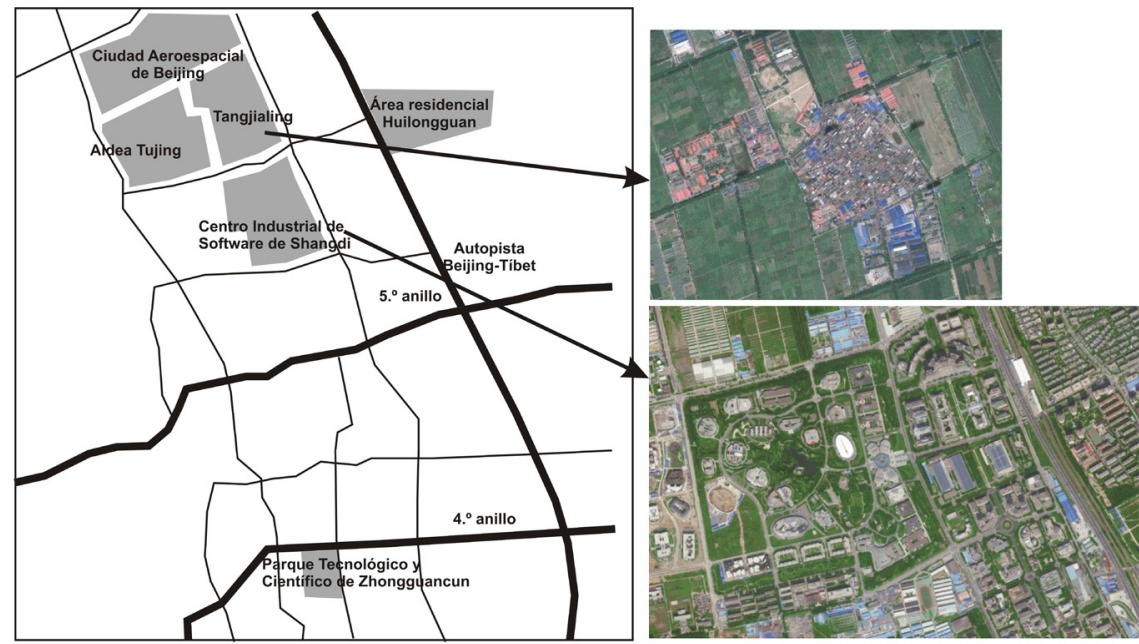

Fuente: Satélite Gaofen-3.

Figura 3. Principales aldeas periurbanas de graduados de bajos ingresos en Beijing

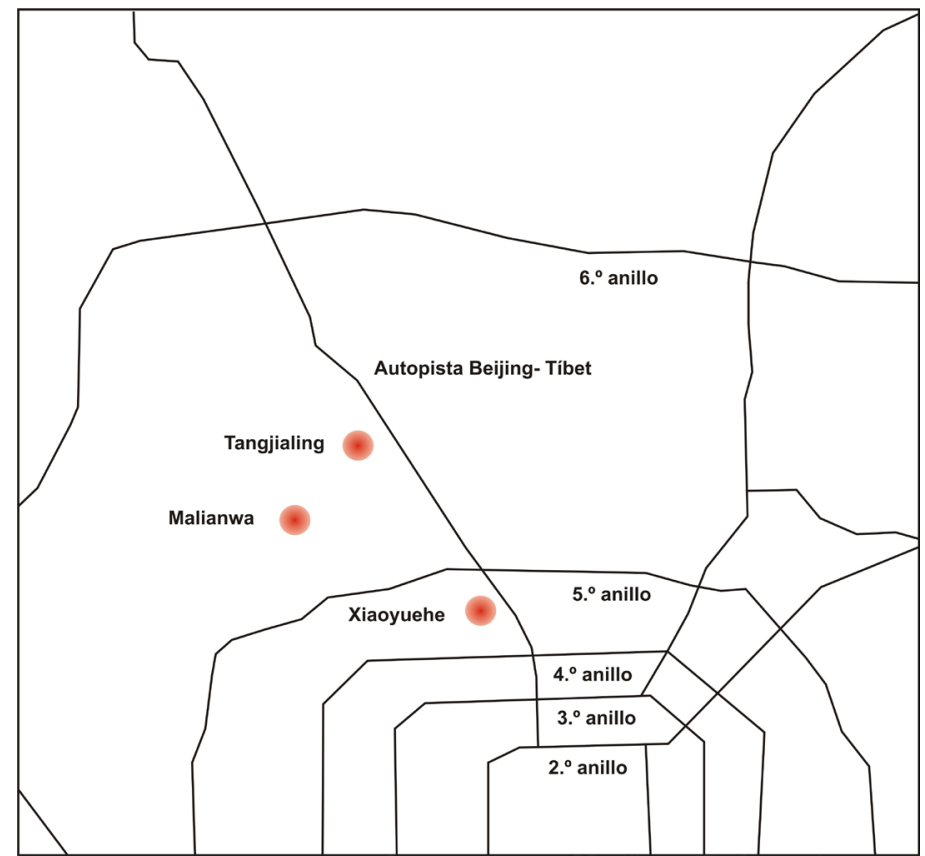

Fuente: elaboración propia a partir de Gu et al., 2013. 
Fotografía 1. Calle principal de la aldea periurbana de Tangjialing

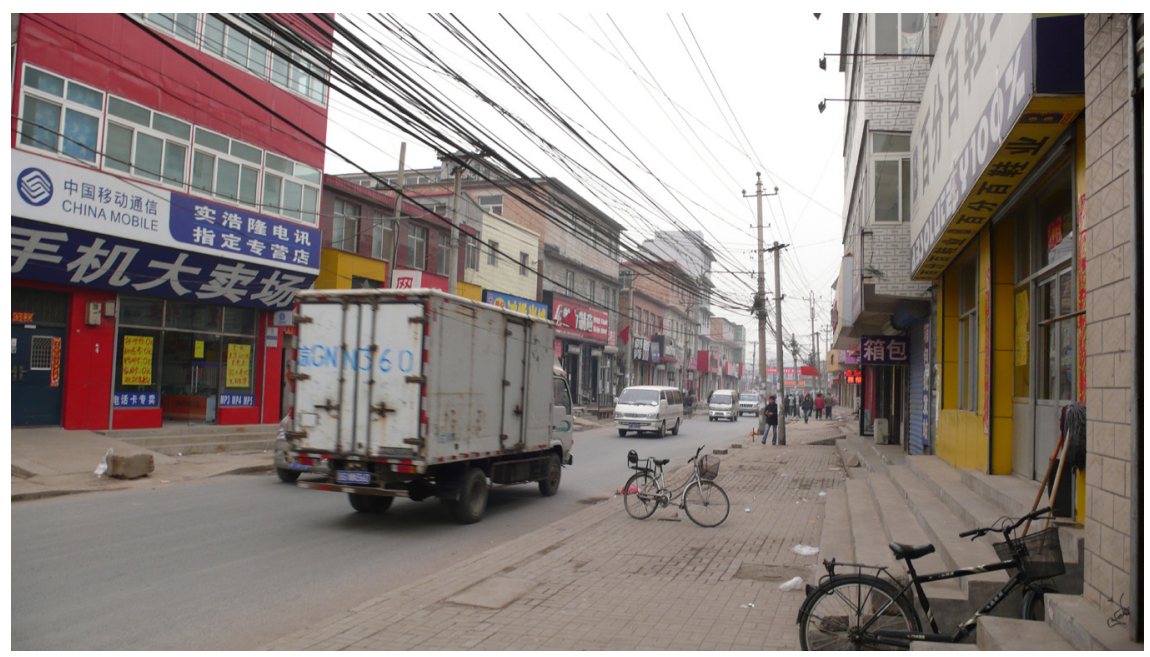

Fuente: elaboración propia.

de los vehículos. Al caminar por ellos, uno puede ver anuncios sobre alquiler de casas y venta de muebles, así como escuchar música alta que proviene de los restaurantes, de las peluquerías y de los cibercafés.

\subsubsection{El ambiente residencial}

La demanda pujante de alquileres provocó una expansión excesiva de la vivienda ilegal en Tangjialing. En el pasado, el paisaje urbano estaba compuesto por hileras de casas de una sola planta ordenadas a ambos lados de la calle, pero, con el tiempo, las viviendas no autorizadas fueron destruyendo el diseño original. Algunas casas tienen tres o cuatro pisos, incluso algunas llegan a los seis o siete pisos. La distancia entre las casas es a veces menor de un metro, lo que crea un serio riesgo para la propagación del fuego, y la proporción entre las legales y las no autorizadas en Tangjialing ha llegado a ser de 1 a 5, según nuestro estudio de campo. El resultado es que la expansión de casas ilegales ha reducido el número de espacios abiertos, al tiempo que el incremento de la población ha sobrecargado las infraestructuras existentes. Tangjialing está siempre en construcción, como lo demuestran los montones de ladrillos existentes por todas partes. Las carreteras son estrechas. La calle principal tiene menos de 10 metros de ancho y, por lo general, está ocupada por coches mal aparcados, lo que provoca graves problemas de congestión. En algunos callejones, dos personas apenas pueden pasar una al lado de otra. Las instalaciones de drenaje a menudo se obstruyen con la lluvia. Y es que, en Tangiialing, los altos precios del suelo determinaron que se aprovechara cada centímetro del mismo para vivienda o actividades comerciales. Incluso el baldío de la zona norte de la aldea es utilizado para el mercado informal o el mercado de las pulgas. 
Fotografía 2. Ambiente residencial en la aldea periurbana de Tangjialing
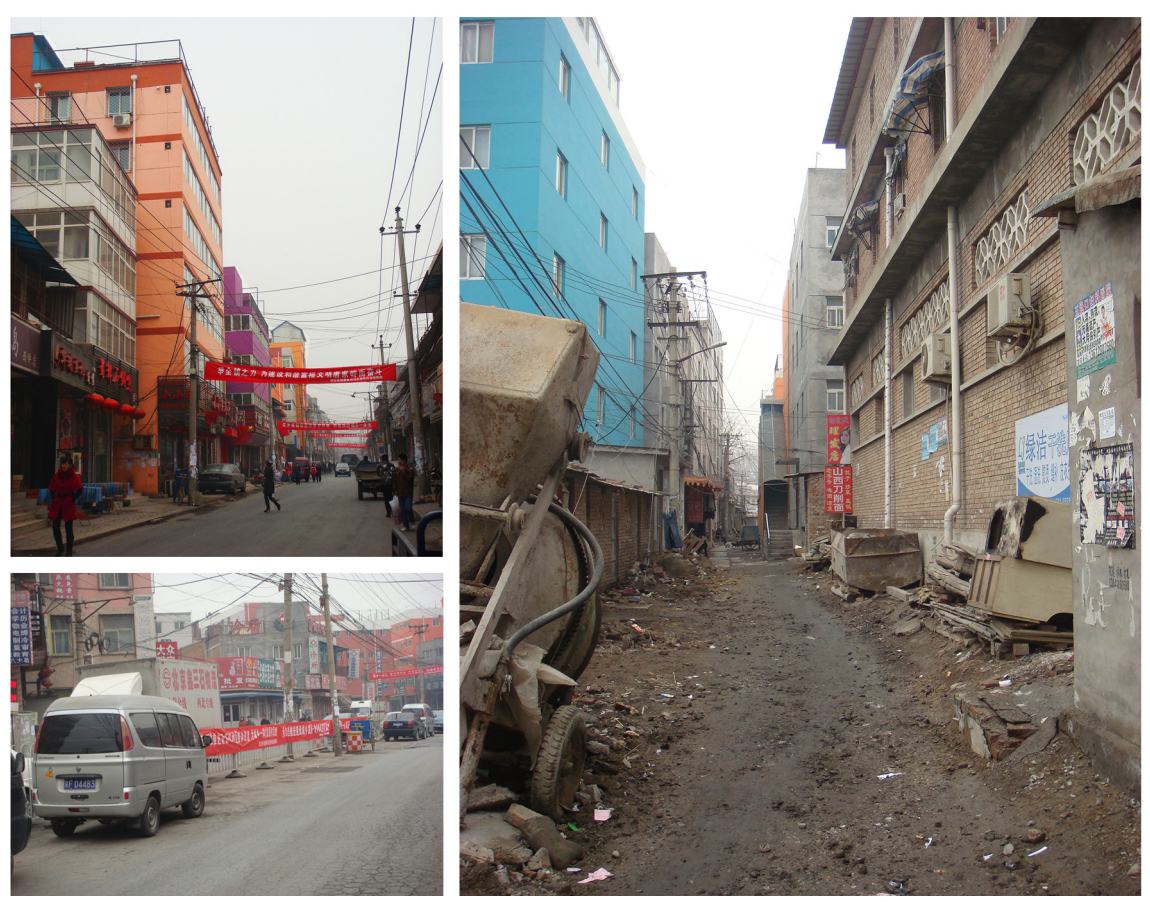

Fuente: elaboración propia.

\subsubsection{Las instalaciones de las viviendas}

Casi todas las casas son de alquiler y cada planta se divide en varias unidades. La habitación más pequeña es de solo unos diez metros cuadrados, que fácilmente se ocupan con una cama, un escritorio y un baúl. Su alquiler sin derecho a baño ni cocina cuesta alrededor de 300 yuanes $^{1}$ al mes, mientras que las habitaciones más caras, sobre 500 yuanes al mes, tienen baños y cocinas privadas, como se pudo comprobar a partir de informaciones de inmobiliarias locales. Sin embargo, alquilar un apartamento de características similares en Zhongguancun cuesta alrededor de 3.000 yuanes. En Tangjialing, entre todos los complejos de viviendas destinadas a alquileres, el de Dong's Grand Courtyard es el de mayor tamaño, con una superficie de 1.300 metros cuadrados y siete plantas en las que se distribuyen 338 habitaciones. Las instalaciones incluyen calentadores solares de agua, aire acondicionado central, guardias de seguridad las 24 horas del día, así como autobuses de transporte gratuito para los inquilinos a la estación del metro de Xi'erqi por la mañana y por la noche.

1. Puesto que, según el tipo de cambio vigente en enero de 2017 , un yuan equivale a 0,14 euros, esta cifra correspondería a 40,7 euros. (N. del e.) 
Fotografía 3. Instalaciones de las viviendas en la aldea periurbana de Tangjialing
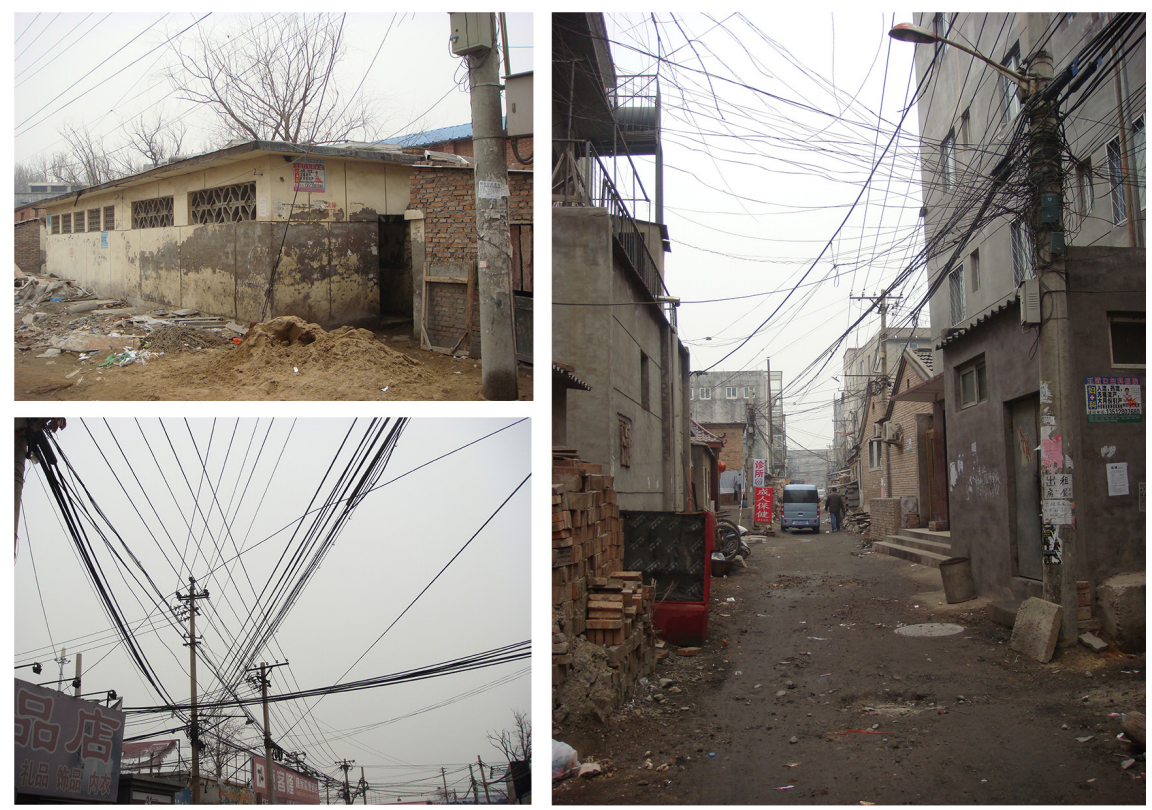

Fuente: elaboración propia.

Con un alquiler de unos 900 yuanes mensuales, el Dong's Grand Courtyard es considerado el complejo de viviendas de alquiler más avanzado y grande de la aldea de Tangjialing, según se pudo observar.

\subsection{El espacio de "La tribu de las hormigas"}

\subsubsection{Un lugar atractivo y asequible}

Hay numerosas líneas de autobús que unen Tangjialing y Zhongguancun con el centro urbano de negocios. La tarifa para un viaje en autobús, utilizando una tarjeta de prepago de tránsito, es de 0,4 yuanes. La estación de metro de Beijing Xi'erqi (línea del metro 13) está cerca y la tarifa para un viaje en metro, incluidas las transferencias, es solo de 2 yuanes. Por otra parte, el alquiler es barato. Un estudio con una superficie construida en torno a los 15-20 metros cuadrados rondaba los 250-900 yuanes antes de 2010 (según encuestas), un precio mucho más bajo que el coste de un apartamento similar en la mayoría de los sectores de Beijing. Además, los inquilinos pueden comprar casi cualquier cosa que necesiten sin tener que pagar demasiado. Por ejemplo, el precio de las verduras plantadas por la población local es casi la mitad que en la ciudad. Con 10 yuanes, se compran los alimentos necesarios para todo un día, y los inquilinos pueden encontrar todo tipo de artículos de primera necesidad en las tiendas de 2 yuanes y de 3 yuanes del entorno. 
Fotografía 4. La aldea periurbana de Tangjialing como un lugar atractivo y asequible
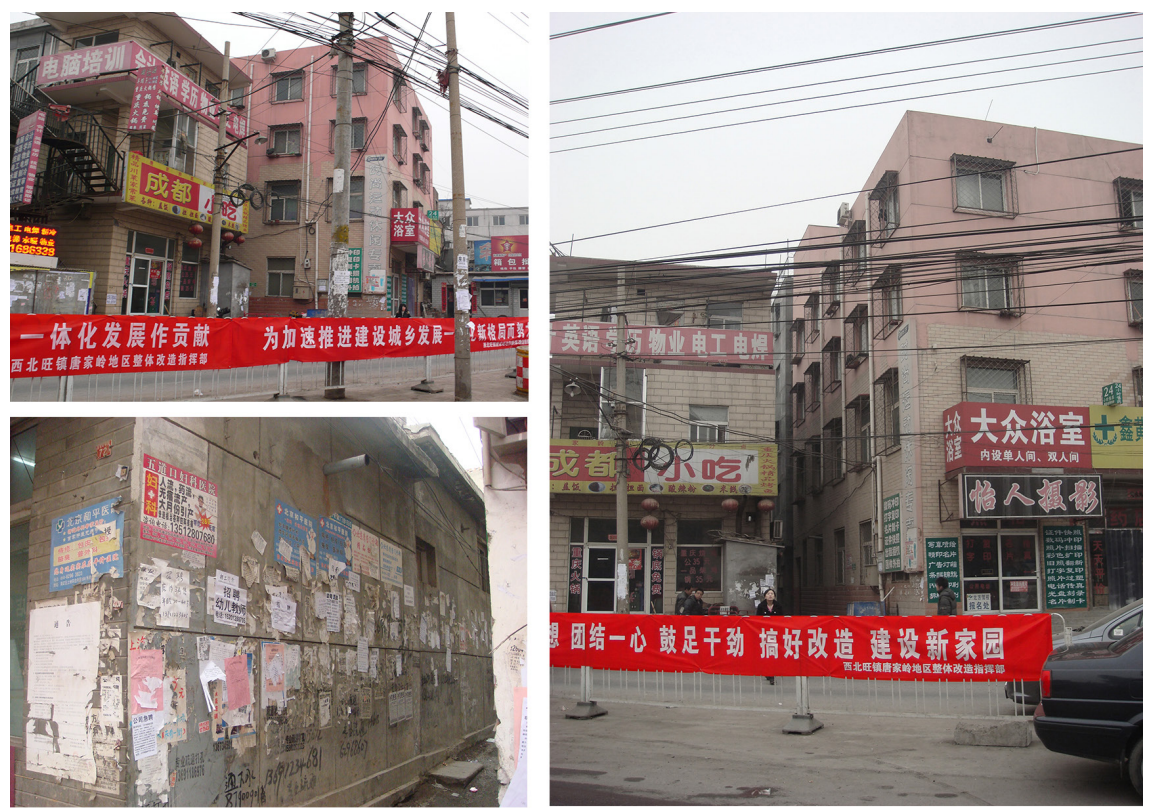

Fuente: elaboración propia.

Fotografía 5. La aldea periurbana de Tangjialing como lugar vibrante
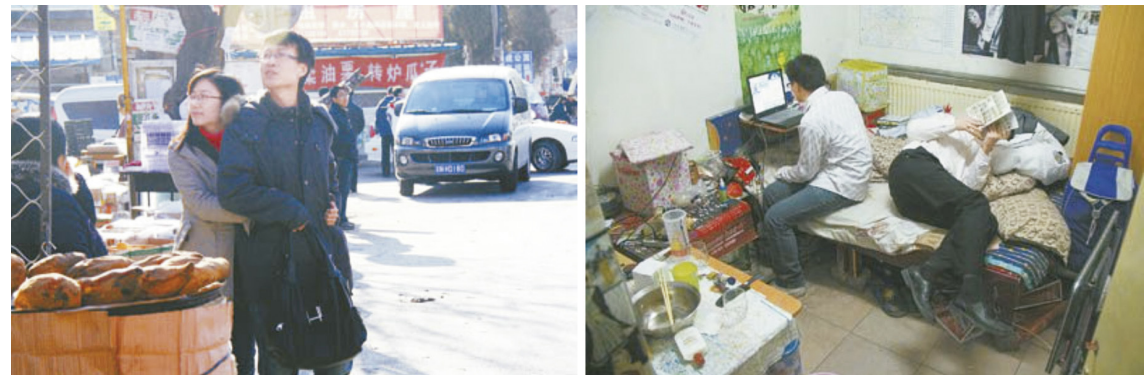

Fuente: elaboración propia.

\subsubsection{Lugar vibrante y móvil}

A pesar de que el entorno físico de Tangjialing es duro o incluso hostil, hay una vida vibrante en la calle y la cultura de la comunidad es rica. Cada mañana, los jóvenes graduados universitarios dejan sus pequeñas habitaciones y comienzan otro día ajetreado. Durante las horas punta, los autobuses circulan 
Fotografía 6. La percepción de la aldea de Tangjialing como lugar de bajos ingresos
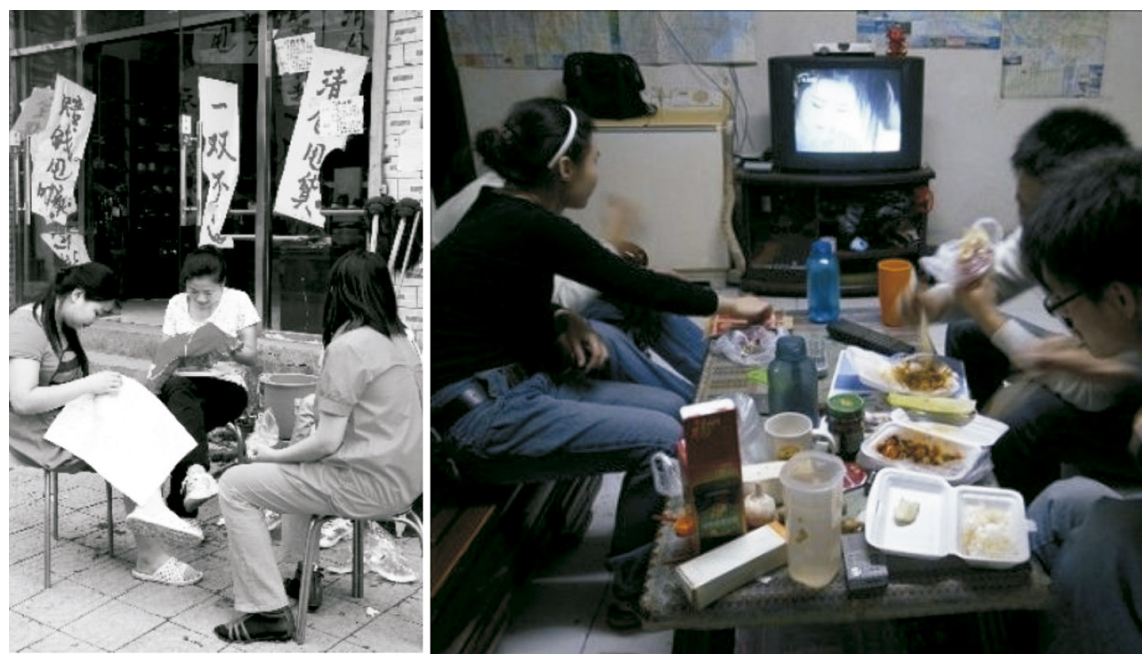

Fuente: elaboración propia.

con demasiada gente, hasta el punto de parecer sardinas en lata. Cuando la oscuridad cae, los graduados regresan del trabajo a sus casas. La vida nocturna también es colorida y estruendosa. Los nuevos graduados pueden disfrutar de fideos con carne por 3 yuanes o celebrar la vida nocturna con sus amigos en puestos de comida, bebiendo, charlando, riendo y así evadir el cansancio de todo el día. Las calles tienen un ambiente en el que se mezclan las risas en puestos de comida, la música de las videotecas, los gritos de los vendedores de comestibles y otros muchos sonidos.

\subsubsection{El sentido de lugar}

$\mathrm{Al}$ vivir en Tangjialing durante mucho tiempo, los graduados de bajos ingresos comienzan a disfrutar de su vida en dicha aldea periurbana. El hecho de tener un pasado similar, de disfrutar de las mismas experiencias, de sentir la soledad, de hacer frente a las dificultades y de mantener el sueño de conseguir vivir una auténtica existencia metropolitana les ayuda a formar redes sociales y a generar una identidad fuerte de grupo. De este modo, Tangjialing proporciona el entorno geográfico para esta nueva comunidad especial, que es distinta de la que existía originariamente en la aldea.

\section{Efectos socioespaciales de la reurbanización en el asentamiento de «La tribu de las hormigas»}

En diciembre de 2010, el Gobierno municipal de Beijing puso en marcha, en la periferia urbana, un plan de renovación de pueblos con altas densidades de población, malas condiciones higiénicas y falta de seguridad pública. Los pue- 
blos de graduados con bajos ingresos desaparecieron en Beijing, incluido el de Tangjialing. A pesar de que las políticas de regulación destruyeron las comunidades de graduados universitarios con bajos ingresos, el fenómeno Tangjialing no desapareció, de modo que están surgiendo muchos nuevos Tangjialings en los suburbios de Beijing.

\subsection{El aumento de la renta después de la demolición}

Desde que comenzó el proyecto de reurbanización, miles de graduados universitarios de bajos ingresos han tenido que abandonar Tangialing y buscar nuevas viviendas. Sin embargo, el precio del alquiler en los suburbios del noroeste de Beijing se ha vuelto inasequible. Por ejemplo, en la aldea de Xiaoniufang, que es adyacente a Tangjialing, el alquiler mensual subió de 450 a $700-800$ yuanes entre 2010 y 2011. Del mismo modo, en el pueblo de la ciudad de Xidian Huilongguan, que también está cerca de Tangjialing, la renta mensual aumentó de $250-450$ a 350-600 yuanes entre 2009 y 2010. Y es que el aumento de la demanda de vivienda de los inquilinos en Tangjialing elevó aún más el precio de alquiler de los barrios vecinos, según fuentes inmobiliarias.

\subsection{La imposibilidad de acceder a apartamentos de cuello blanco}

De acuerdo con la Solución de Ejecución para la Reconstrucción General en el área de Tangjialing, promovida por el Gobierno municipal de Beijing, además de viviendas para el asentamiento de los pobladores reubicados y de suelo industrial multifunción, está previsto construir 100.000 metros cuadrados de viviendas públicas de bajo alquiler en Tangjialing, conocidas como «apartamentos de cuello blanco», para los trabajadores de alta tecnología del Parque Científico y Tecnológico de Zhongguancun. Sin embargo, si se toma como referencia el precio que alcanzan en el mercado apartamentos de la misma zona con características similares, se prevé que la renta mensual media supere los 1.000 yuanes para los apartamentos con un solo dormitorio. Y lo que es peor, en julio de 2010, la Oficina de Seguridad de la Vivienda de Beijing declaró que los solicitantes que no tengan registro de residencia de Beijing no podrán acceder a las viviendas públicas de alquiler bajo. Los graduados universitarios de bajos ingresos, que una vez vivieron en Tangjialing, no solo se encontrarán con rentas más elevadas, sino que también van a ser excluidos de los apartamentos de cuello blanco, puesto que no están registrados como residentes en Beijing.

\subsection{El nuevo fenómeno Tangjialing}

La aldea de Tangjialing, aquel lugar en el que solían vivir los graduados universitarios con bajos ingresos, ha desaparecido. Los alquileres de las aldeas cercanas se han incrementado más allá del nivel asequible para aquellos jóvenes. 
Fotografía 7. Trasladando a graduados de bajos ingresos de la aldea periurbana de Tangjialing
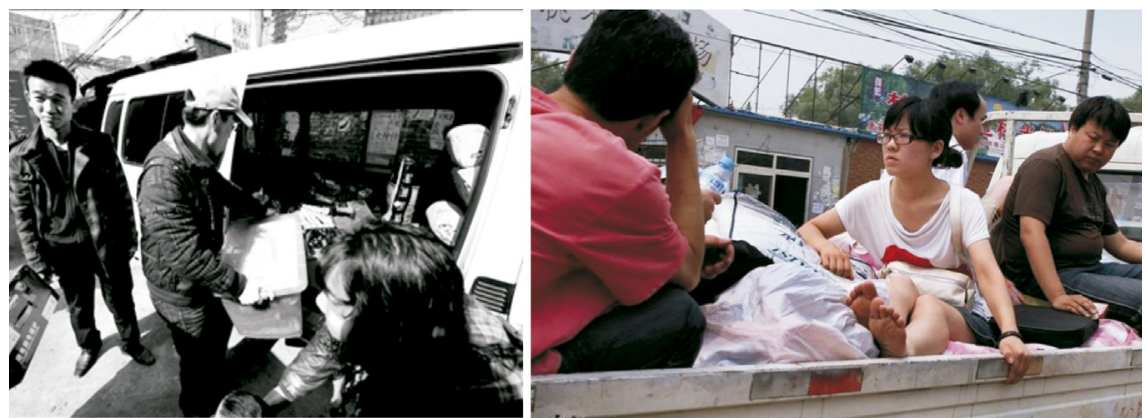

Fuente: elaboración propia.

Concretamente, en los grandes distritos residenciales como Huilongguan y Tiantongyuan, la renta ha aumentado en un 30\%, según datos de la ciudad. Por lo tanto, los graduados universitarios con bajos ingresos tienen que pulular por los pueblos periurbanos que quedan cerca de Tangjialing. Un nuevo fenómeno Tangjialing está emergiendo.

Algunas aldeas urbanas que son adyacentes a Tangjialing, como Xiaoniufang, Shigezhuang y Liulitun, y otras más alejadas, como Xiyuan, Fenghuying, Banbicun oriental y occidental y Huoying, se han convertido en los nuevos asentamientos para graduados universitarios con bajos ingresos. Banbicun Este, localizado cuatro kilómetros al norte de Tangjialing, es un típico pueblo rural del suburbio de Beijing en el que la mayoría de las casas originales de la aldea se han ido transformado en apartamentos de bajo alquiler. Una habitación de doce metros cuadrados, orientada al sur, con algunos muebles básicos (una cama, un armario, un escritorio y un aparato de aire acondicionado) y el acceso gratuito a Internet, le cuesta al inquilino más de 480 yuanes al mes, como apuntaron diversas encuestas. El alquiler en Banbicun oriental es mucho más alto que en el Tangjialing original.

Concretamente, esto sucede en Shigezhuang, Banbicun oriental y occidental, que están al lado de la autopista Beijing-Tíbet, y se han conectado entre sí por tener medios de transportes cómodos y alquileres baratos. Al inicio de la demolición de Tangjialing, algunos de los pueblos de los alrededores se anunciaban para atraer a las «hormigas». Cerca de 41.000 personas migraron desde Tangjialing desde julio de 2010, la mayoría de ellos, sobre unos 15.000, se trasladaron a Shigezhuang y la Banbidian Oeste, distrito de Changping; otras 12.000 personas se trasladaron a las zonas de los alrededores, como Xibeiwang, y 14.000 personas migraron a la periferia urbana del distrito de Haidian (figura 4). Ahora, el área cuenta con casi 150.000 personas y su tamaño va más allá de del Tangjialing original. 
Figura 4. Difusión espacial del asentamiento gregario de Tangjialing

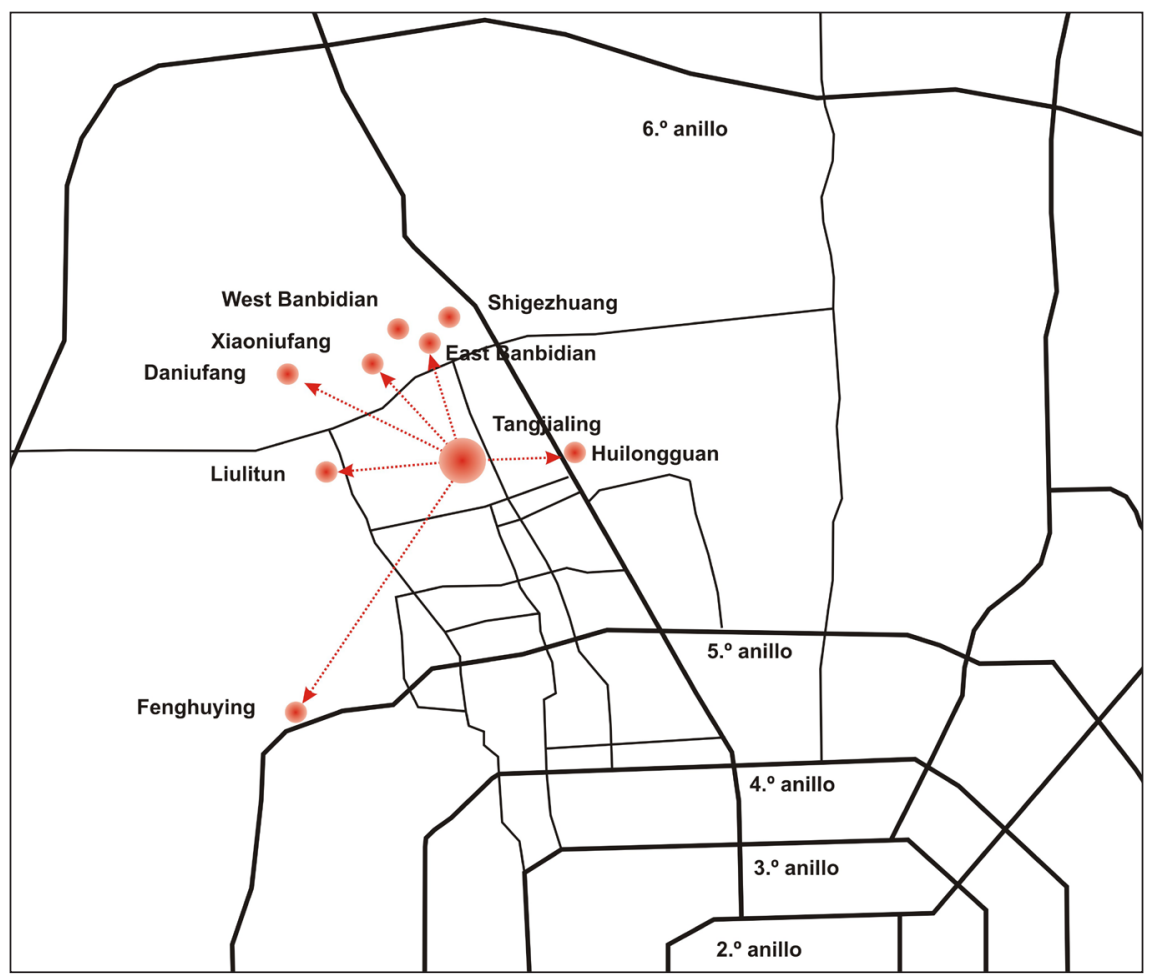

Fuente: elaboración propia.

\section{Nuevos cambios en los asentamientos de «La tribu de las hormigas»}

\subsection{Shigezhuang: la formación de una nueva "tribu de las hormigas"}

Shigezhuang se ha convertido en el mayor y nuevo foco de las «hormigas» migrantes. Se encuentra ubicado en el distrito de Changping, entre la estación de tren de Beijing-Zhangjiakou y la autopista Beijing-Tíbet. Incluye cuatro

Fotografía 8. Una nueva «tribu de hormigas»: la aldea periurbana de Shigezhuang, en Beijing

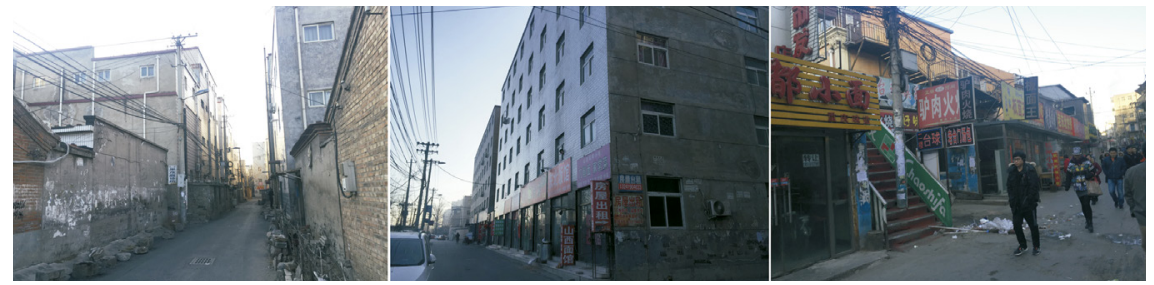

Fuente: elaboración propia. 
aldeas administrativas, el pueblo Shigezhuang, la aldea Banbidian este, el pueblo Banbidian oeste y la aldea Dingfuhuangzhuang, todos ellos núcleos periurbanos que abarcan una superficie total de 119 hectáreas. Tiene una población residente de 54.417 personas, de las cuales 6.525 son residentes nativos desde finales de 2011 (datos tomados del censo).

Durante los días 16 a 18 de noviembre de 2012, se realizó una encuesta a 544 personas, aproximadamente el 1\% de la población total de Shigezhuang. Tal como se muestra en la figura 5, las viviendas encuestadas se distribuyeron de manera relativamente uniforme. Del total de cuestionarios, se contestaron 498, 461 de los cuales fueron válidos y con respuestas cualificadas. De esta forma, el grado de fiabilidad de la encuesta se estimó en un 92,6\%. La figura 6

Figura 5. Distribución de los 544 cuestionarios que formaron la muestra de la encuesta de Shigezhuang en el periodo del 16 al 18 de noviembre de 2012

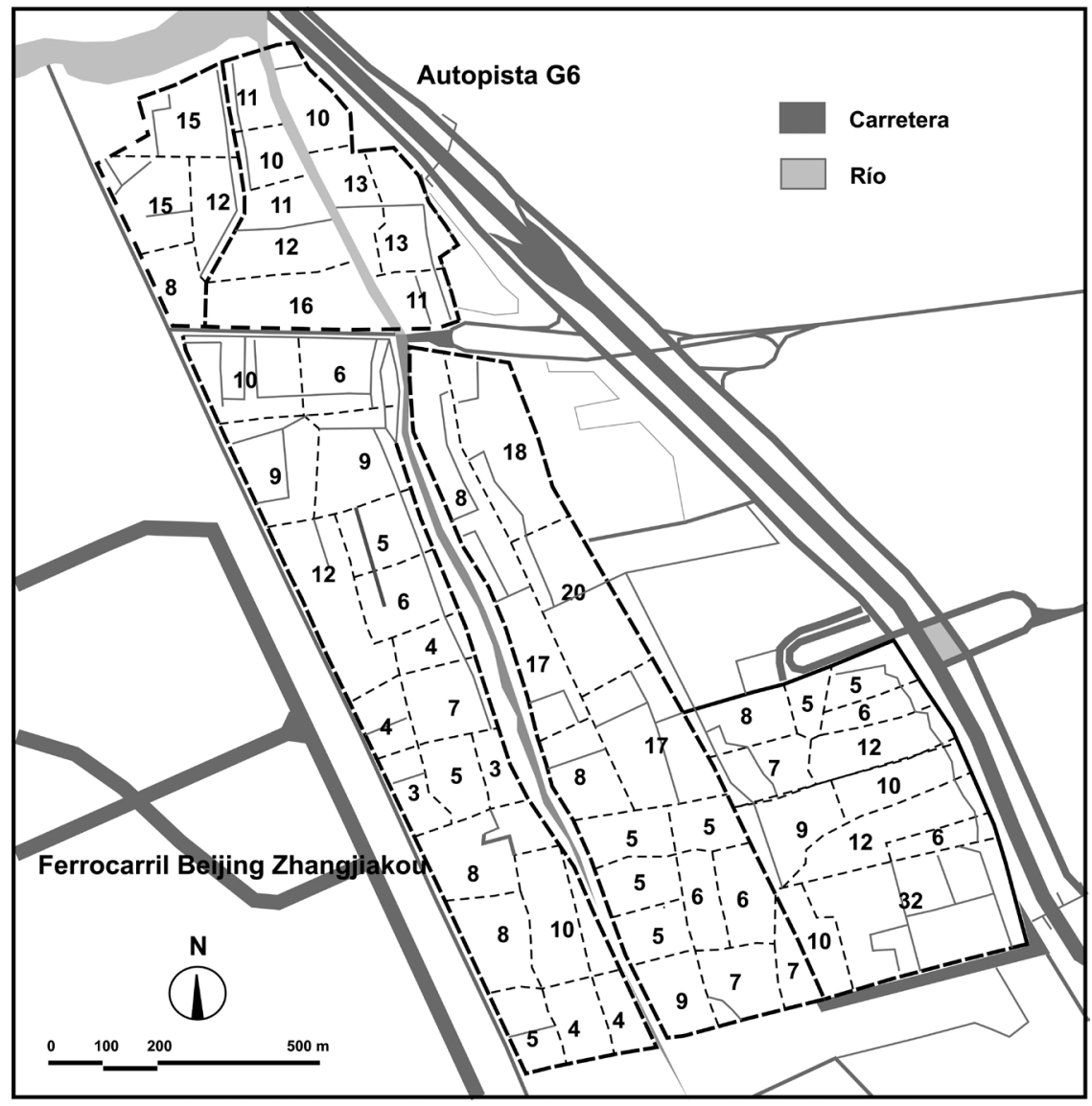

Fuente: elaboración propia. 
Figura 6. Títulos académicos de la población fluctuante en Shigezhuang (año 2012)

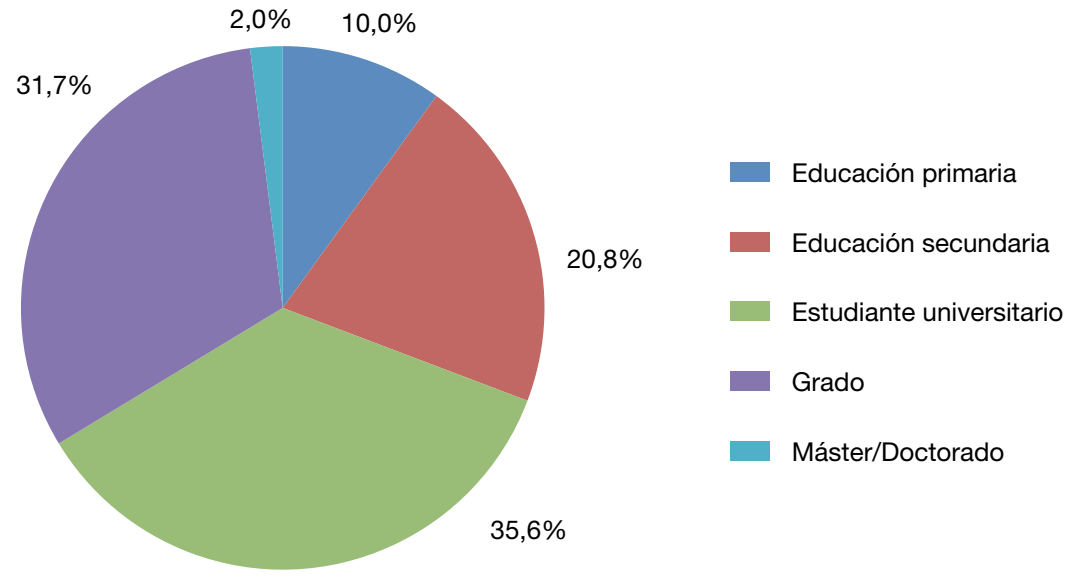

Fuente: encuesta.

Fotografía 9. Altas densidades de población en la nueva «tribu de las hormigas» de Shigezhuang
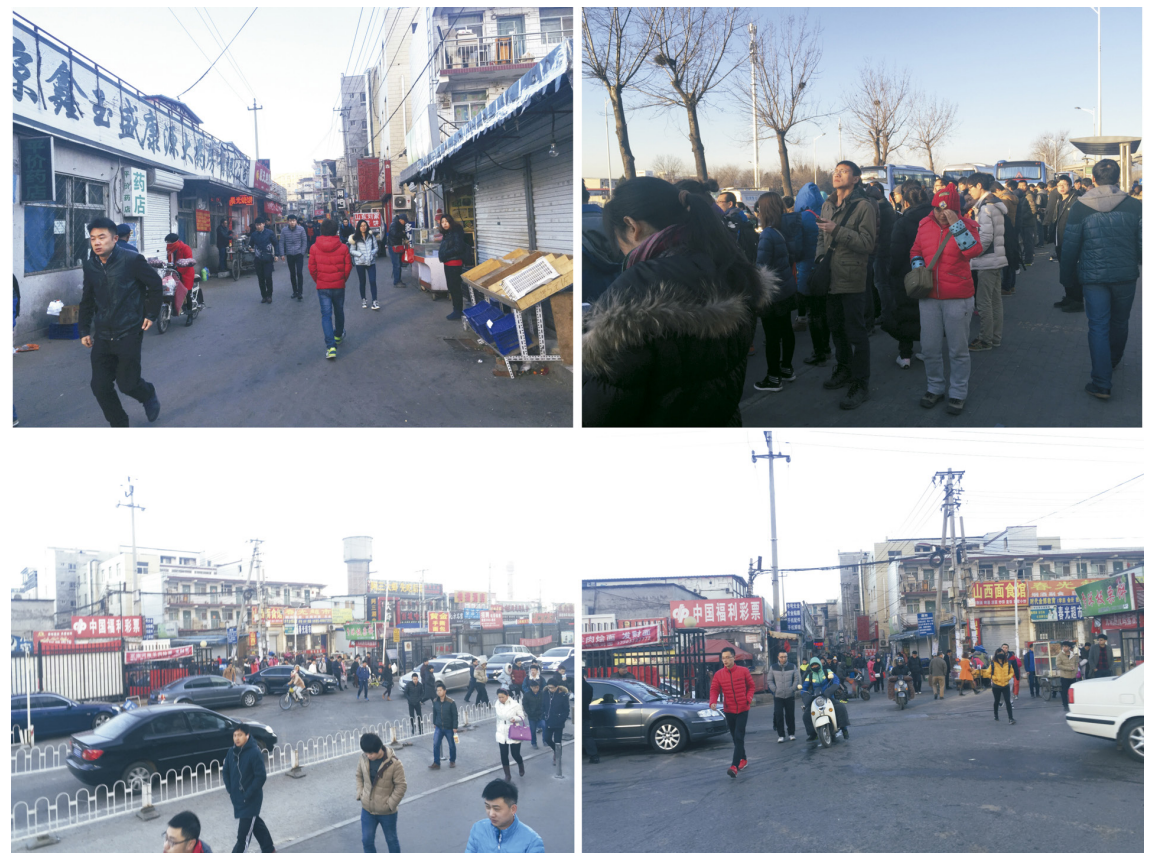

Fuente: elaboración propia. 
Figura 7. Principales ocupaciones de los graduados en Shigezhuang

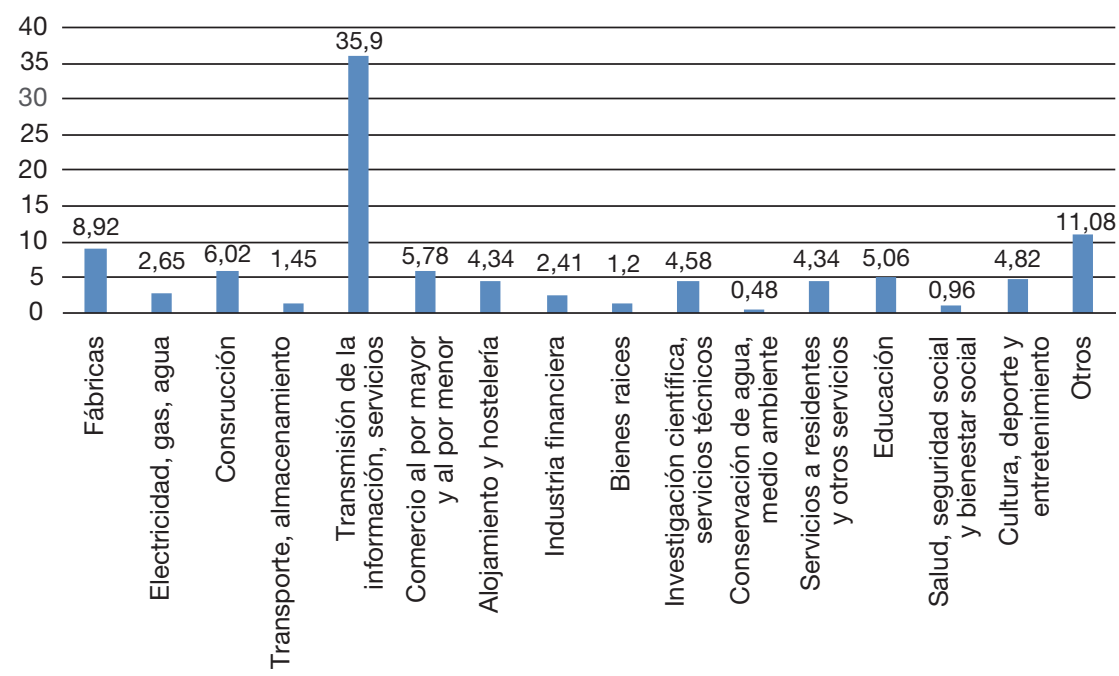

Fuente: Censo de población (2011).

muestra el nivel educativo de las personas encuestadas y refleja que el 69,2\% se corresponde a estudiantes de posgrado.

Shigezhuang presenta poca diferencia de la Tangjialing original. Su densidad de población alcanza las 46.000 personas por kilómetro cuadrado. La zona no tiene espacios abiertos y está llena de edificios de 4 a 6 plantas para

Figura 8. Distribución de los trabajos en la «tribu» de Shigezhuang

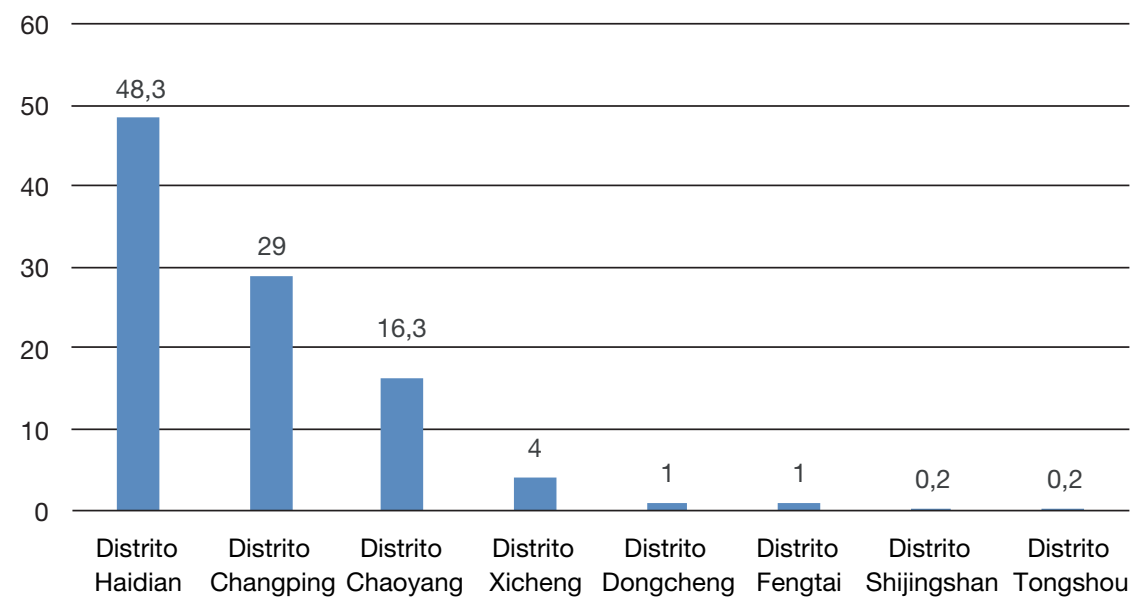

Fuente: Censo de población (2011). 
alquilar. El 47,3\% de los encuestados indicó que hacía menos de un año que residía en el área Shigezhuang.

La encuesta también mostró que las principales actividades en las que trabajan los estudiantes de posgrado son las relacionadas con la transmisión de información, los servicios de informática y la industria del software (35,9\%), la industria manufacturera $(8,92 \%)$ y la construcción $(6,02 \%)$, así como el comercio al por mayor y al por menor (5,78\%) (figura 7$)$. Se trata de unos empleos que se concentran principalmente en la zona de Shigezhuang, así como en el distrito de Haidian (48,3\%), el distrito de Changping (29,0\%) y el distrito de Chaoyang (16,3\%) (figura 8).

\subsection{Tangjialing: la pérdida de la antigua "tribu de hormigas"}

El 15 de julio de 2013, se llevó a cabo otra encuesta en la reconstruida Tangjialing. Los resultados que se obtuvieron demostraron que, con la nueva ciudad, había desaparecido todo lo relacionado con la Tangjialing original.

\subsubsection{El regreso de los residentes}

El proyecto de reconstrucción de Tangjialing supuso la eliminación de la

Fotografía 10. El lugar originario de la aldea periurbana de Tangjialing se ha transformado en un parque forestal del distrito de Haidian
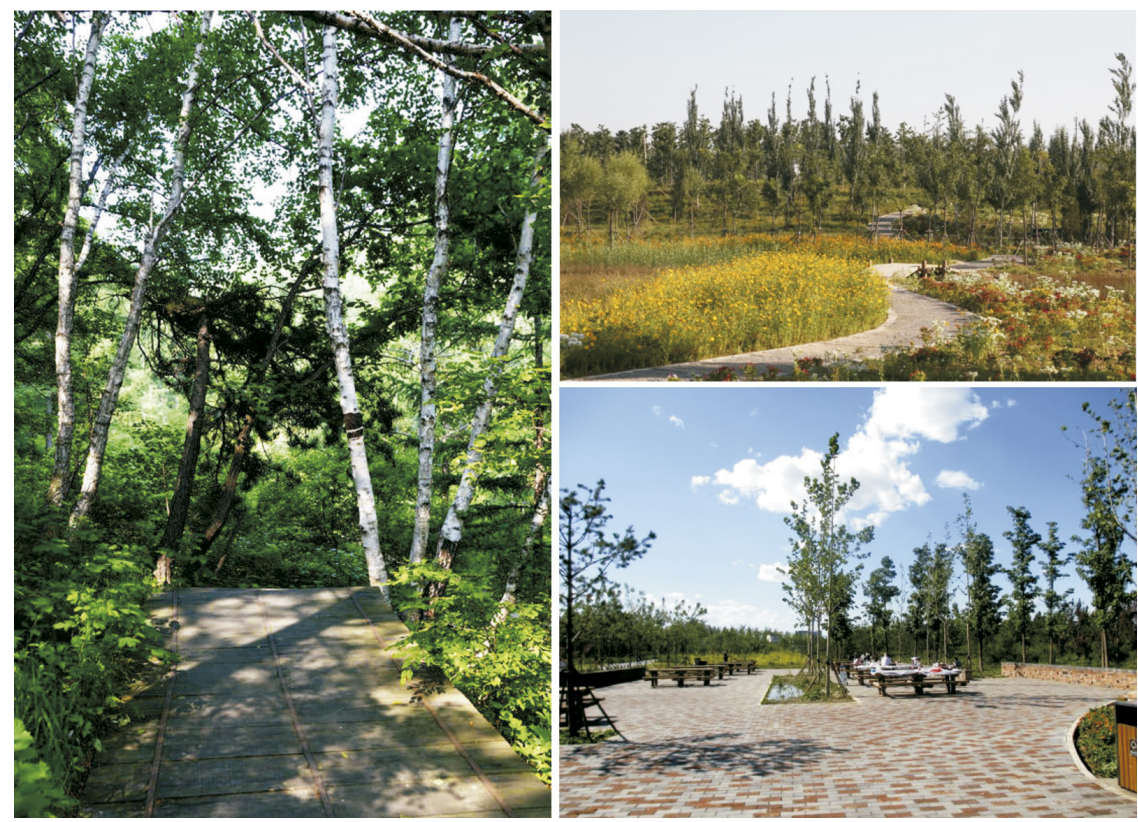

Fuente: elaboración propia 
Fotografía 11. La nueva ciudad residencial de Tangjialing en Beijing

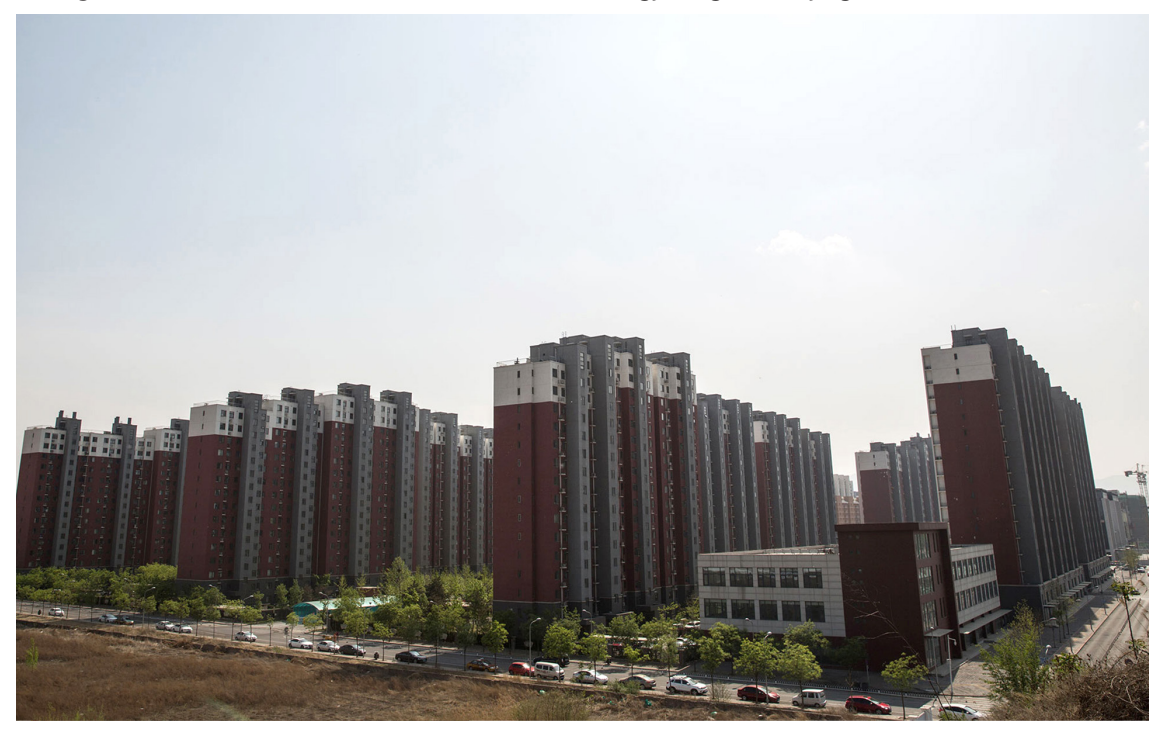

Fuente: elaboración propia

aldea periurbana original y la construcción de una nueva ciudad residencial. El objetivo principal del proyecto fue la edificación de espacios de vida para los agricultores y para los estudiantes graduados de bajos ingresos del pueblo de Tangjialing y la aldea Tujin. La superficie total destinada a la construcción fue de $130.000 \mathrm{~m}^{2}$ y de $10.000 \mathrm{~m}^{2}$ para espacios verdes. Las viviendas destinadas al realojo, junto con los edificios reservados a equipamientos educativos, supusieron un total de $260.000 \mathrm{~m}^{2}$ (excluyendo las zonas subterráneas). La vivienda es compacta y su superficie suele estar en torno a los 75, los 83 y los $100 \mathrm{~m}^{2}$. La mayoría de los residentes se mudaron a la nueva ciudad de Tangjialing el 10 de diciembre de 2012. Los aldeanos, cuyas casas originales tenían en torno a los 150-200 $\mathrm{m}^{2}$, recibieron una compensación por la demolición de las mismas, según informaciones oficiales. Esta consistió en cuatro apartamentos de $80 \mathrm{~m}^{2}$ cada uno. El estándar de la compensación por demolición era que cada aldeano pudiese conseguir un apartamento nuevo de $65 \mathrm{~m}^{2}$ de superficie. Si, antes de la demolición, su vivienda superaba el nivel de la compensación por demolición, podían comprar pisos en excedente a un menor precio, que estaría en torno a los 3.800 yuanes el $\mathrm{m}^{2}$. Las nuevas casas asignadas tenían licencia de bienes raíces, pero no podían entrar en el mercado de la vivienda en venta. Si una casa quería venderse, tenía que ser devuelta a la oficina de la vivienda de Tangjialing por un precio de 15.000 yuanes el $\mathrm{m}^{2}$ y convertirse en una vivienda asequible. En la nueva ciudad Tangjialing, se construyeron cerca de 3.000 viviendas. A excepción de los 1.600 pobladores originales que ocupan 800 nuevas viviendas, hay cerca de 2.200 viviendas en alquiler para trabajadores de cuello blanco de 
Fotografía 12. Los antiguos pobladores de Tangjialing regresan a la nueva ciudad residencial
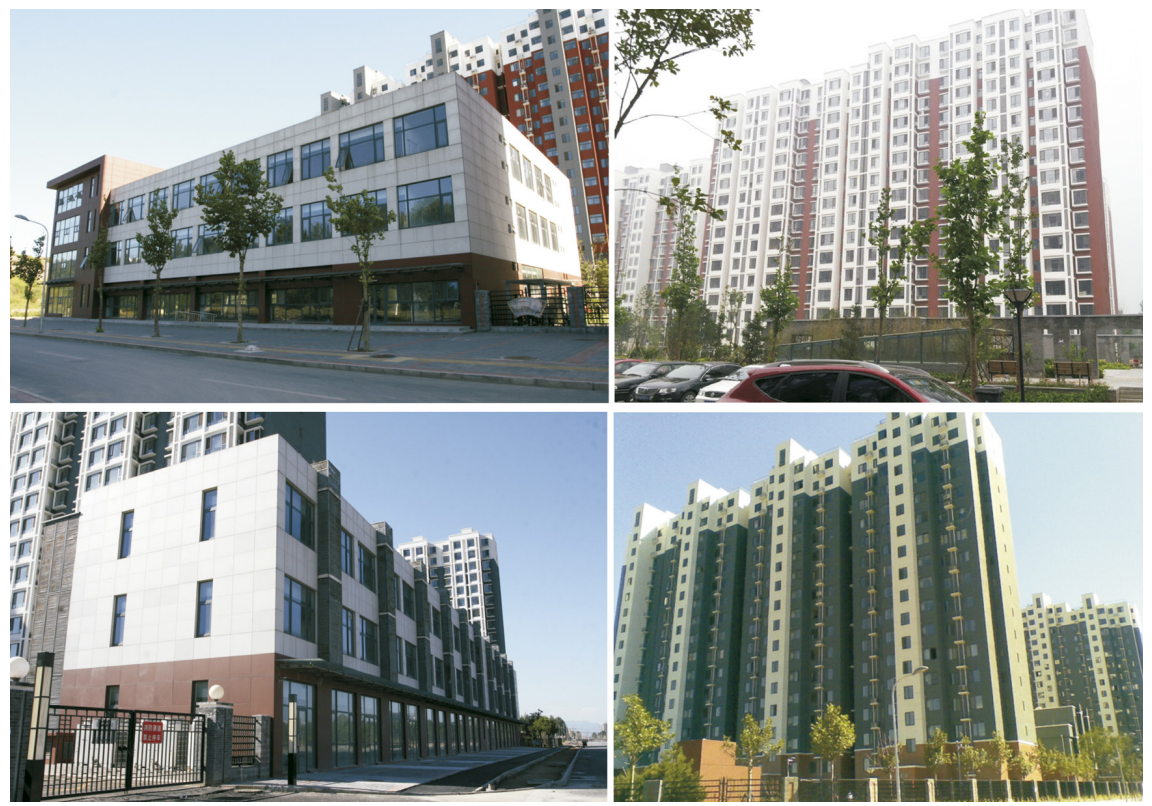

Fuente: elaboración propia

bajos ingresos. Se prevé que la población total que acogerá la nueva ciudad de Tangjialing será de 10.000 personas, una cifra mucho menor en comparación con la población original, que era de 60.000 personas, y que determinará una disminución de las densidades de población.

\subsubsection{Pero las líneas de autobuses no volvieron}

Con anterioridad al proyecto de reconstrucción del pueblo de Tangjialing, había cinco líneas de autobuses que pasaban por el mismo. Ahora, una amplia zona de la aldea original Tangjialing se ha transformado en un parque forestal y todas las líneas de autobuses han sido desviadas. Existen solo tres paradas de autobús a lo largo de dos kilómetros en la nueva ciudad de Tangjialing, así como dos líneas de autobús originales que conectan la zona sur de la Ciudad Aeroespacial — que está a un kilómetro de Tangjialing — con la ciudad nueva. Por consiguiente, una vez completada la construcción de la nueva ciudad residencial de Tangjialing, tanto los pobladores originales que se trasladaron a la misma como los nuevos residentes, se encuentran con el problema de desplazarse en autobús, teniendo que recurrir al uso de coches particulares o a caminar durante media hora para llegar a una de las paradas más cercanas a sus domicilios.

\subsubsection{Viviendas con alquileres inasequibles}


Fotografía 13. Viviendas inasequibles para inquilinos de bajos ingresos en Tangjialing
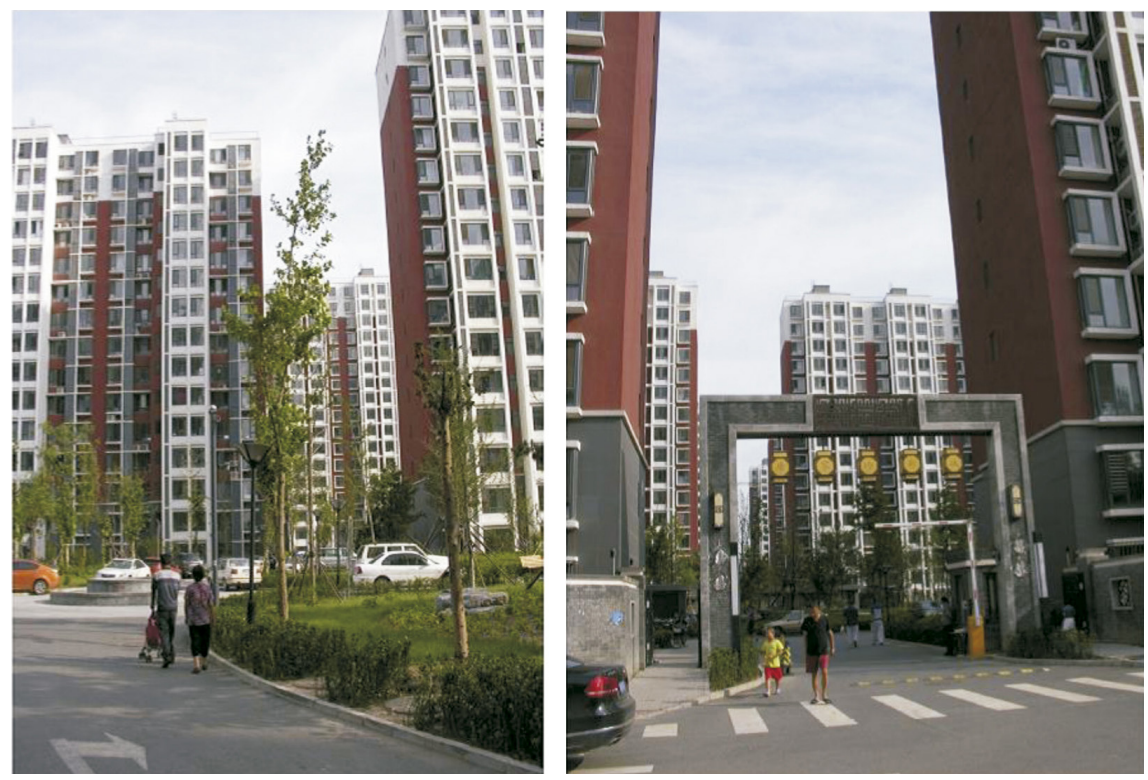

Fuente: elaboración propia

A partir de datos oficiales, se contabilizan más de 3.000 apartamentos en la zona, 2.000 unidades de los cuales se pueden alquilar para los migrantes, a través de la oficina para la vivienda, por un alquiler que ronda los 2.100-3.600 yuanes al mes. Los inquilinos tienen que formalizar el importe correspondiente a 12 meses de alquiler en un solo pago y comprometerse a abonar un incremento del $10 \%$ del arrendamiento en un periodo de 3 años. Sin embargo, la mayoría de las «hormigas» solo puede permitirse pagar 1.000 yuanes de alquiler mensual, pues el promedio de sus ingresos es de 3.500 yuanes al mes.

\subsubsection{Los ingresos de los aldeanos disminuyen rápidamente}

Según nuestro trabajo de campo, la principal fuente de ingresos para la comunidad anterior eran los alquileres de "La tribu de las hormigas», pero ahora se han perdido dichos recursos, puesto que «La tribu de las hormigas» no va a regresar. Además, debe afrontar el pago de sus casas nuevas, lo que supone que cada hogar tiene que gastar sobre 600.000 yuanes y desprenderse básicamente de todos los ahorros familiares. Ahora, el ingreso promedio por hogar es de 7.500 yuanes al mes, mucho menos en comparación con el ingreso medio anterior. Los habitantes del pueblo tienen dos recursos principales de ingresos:

a) El salario: la mayoría de los aldeanos están sin trabajo y su tasa de desempleo es superior al $70 \%$. La comunidad solo puede proporcionar puestos 
laborales de baja remuneración, como conserjes, limpiadores o trabajadores forestales, entre otros, con un salario mensual de solo 1.270 yuanes. Algunas personas se ven obligadas a conducir taxis sin licencia, como los que van desde la nueva ciudad de Tangjialing hasta la estación de metro. Una ocupación que puede suponer ingresos de 1.500 a 2.000 yuanes por mes.

b) Los alquileres: dos alquileres pueden generar ingresos de 5.400 yuanes al mes.

Por otra parte, los gastos familiares han aumentado rápidamente y se han situado en torno a 3.000 yuanes al mes, debido a que viven en una comunidad de características urbanas. Esto supone que hay que pagar:

a) Una cuota a la municipalidad en torno a los 1.100 yuanes por cada vivienda en base a una tasa de 2,75 yuanes el $\mathrm{m}^{2}$ y una tarifa de aparcamiento adicional.

b) El coste básico de la vida, que se sitúa en 1.900 yuanes/mes por familia.

\section{Conclusiones}

La aparición de «La tribu de las hormigas» está relacionada con algunos cambios recientes en las políticas de urbanización y mejores niveles de vida en China. Reducir el número de agricultores y promover el desarrollo económico y social de las zonas rurales han sido factores clave en la transición social del país. Al mismo tiempo, la urbanización requiere mano de obra urbana y consumidores de productos ciudadanos, por lo que se piensa que la educación es la manera más barata y efectiva para preparar a la mano de obra urbana y a los consumidores. Sin embargo, la demanda de empleo no ha crecido de manera suficientemente rápida para absorber la gran cantidad de fuerza de trabajo altamente capacitada que se ha preparado. Por consiguiente, numerosos graduados universitarios tienen dificultades para encontrar empleos bien pagados en las grandes ciudades. Mientras tanto, el incremento de los gastos sociales y el coste de la vida, especialmente en el caso de la vivienda, les impone una gran presión; de ahí que muchos graduados universitarios se conviertan en trabajadores de bajos ingresos que solo pueden permitirse el lujo de vivir en aldeas periurbanas.

El asentamiento de "La tribu de las hormigas», es decir, de los graduados universitarios de bajos ingresos en Beijing, define algo así como la segunda generación de población migrante urbana. Además, constituye uno de los dos nuevos grupos sociales desfavorecidos surgidos a raíz del proceso de urbanización de China desde el año 2000. Los graduados universitarios de bajos ingresos provienen principalmente de las zonas rurales y están familiarizados con el estilo de vida de pueblos urbanos. Han recibido educación superior y abrazan la expectativa de conseguir una vida ciudadana. Sin embargo, aunque se piensa que una educación cualificada es la forma más barata y eficiente para acelerar la urbanización, su rápida expansión ha producido un efecto secundario adverso: la aparición de un nuevo grupo social marginal de los graduados universitarios de bajos ingresos, que están aislados y excluidos de la corriente principal de la sociedad metropolitana en términos de empleo y de asentamientos. 
En resumen, la concentración de los graduados universitarios de bajos ingresos en zonas edificadas deficientes es un fenómeno que ha tenido lugar en un periodo concreto del proceso de urbanización en China. Las aldeas periurbanas sirven de refugio temporal a estos grupos marginales y de trampolín para su integración en la sociedad metropolitana. Sin embargo, es necesario mejorar la calidad del entorno construido en aldeas urbanas. El fenómeno Tangjialing está profundamente arraigado en el particular proceso de urbanización de China, y se caracteriza por una estrategia que mezcla el favorecer conjuntamente la educación superior y el legado socialista persistente de la división entre el mundo de la ciudad y el del campo.

\section{Agradecimientos}

Agradecemos la colaboración de la fundación Filosofía y Planificación de Proyectos de Ciencias Sociales en Beijing, así como los valiosos comentarios del profesor Ian Cook.

\section{Referencias bibliográficas}

Chen, A. y Coulson, N.E. (2002). «Determinants of Urban Migration: Evidence from Chinese Cities» Urban Studies [en línea], 39 (12), 2189-2197. $<$ http://dx.doi.org/10.1080/0042098022000033818>

Chen, G.; Gu, C. y Wu, F. (2004). «Spatial Analysis of Urban Poverty in Nanjing». Scientia Geographica Sinica [en línea], 24 (5), 542-549. Edición original en chino.

- (2006). «Urban poverty in the transitional economy: A case of Nanjing, China». Habitat International [en línea], 30 (1), 1-26. <http://dx.doi.org/10.1016/j.habitatint.2004.06.001>

Chung, H. (2010). «Building an image of villages-in-the-city: A clarification of China's distinct urban spaces». International Journal of Urban and Regional Research [en línea], 34 (2), 421-437. <http://dx.doi.org/10.1111/j.1468-2427.2010.00979.x>

FenG, J. (2004). Chinese urban internal spatial restructure in transition. Beijing: Science Press. Edición original en chino.

FenG, J.; Wu, F. y Logan, J. (2008). «From homogenous to heterogeneous: The transformation of Beijing's socio-spatial structure». Built Environment [en línea], 34 (4), 482-498. <http://dx.doi.org/10.2148/benv.34.4.482>

Franklin, B. y TaIt, M. (2002) «Constructing an image: The urban village concept in the UK». Planning Theory [en línea], 1 (3), 250-272. $<$ http://dx.doi.org/10.1177/147309520200100304>

Gans, H. (1962). The urban villagers. Nueva York: Free Press.

Gaubatz, P. (1995). «Urban transformation in post-Mao China: Impacts of the reform era on China's urban form». En: Davis, D.S.; Kraus, R.; Naughton, B. y Perry, E.J. (eds.). Urban spaces in contemporary China. Cambridge: Cambridge University Press, 28-60.

Gu, C.; Chan, R.C.; Liv, K.J. y Kesteloot, C. (2006). «Beijing's Socio-Spatial Restructuring: Immigration and Social Transformation in the Epoch of National 
Economic Reformation». Progress in Planning [en línea], 66 (4), 242-310. <http://dx.doi.org/10.1016/j.progress.2006.10.001>

Gu, C.; Chen, G. y Wu, F. (2010). «New Urban Poverty Transitional Economy: Evidence from Beijing and Nanjing». Science Reports of Tohoko University 7th Series (Geography), 57 (1/2), 1-23.

Gu, C. у Kesteloot, C. (1997). «Beijing Socio-spatial Polarization and Segregation». Geographica Sinica, 52 (5), 385-393. Edición original en chino.

- (2002). «Beijing's socio-spatial structure in transition». En: Schnell, I. y OstenDORF, W. (ed.). Studies in segregation and desegregation. Aldershot: Ashgate, 285-311.

Gu, C. y Liu, H.Y. (2001). «Social polarization and segregation in Beijing». En: Logan, J.R. (ed.). The new Chinese city: Globalization and market reform. Oxford: Blackwell Publishing Limited, 198-211.

Gu, C. y SHEN, J. (2003). «Transformation of urban socio-spatial structure in socialist market economies: The case of Beijing». Habitat International [en línea], 27 (1), 107-122. <http://dx.doi.org/10.1016/S0197-3975(02)00038-3>

Gu, C. y Sheng, M. (2012). "Beijing's ant tribe: A case study of Tangjialing». Human Geography, 5, 20-24. Edición original en chino.

Gu, C.; Sheng, M. y Hu, L. (2013). «Study on gregarious low-income college graduates in Beijing: Tangjialing Phenomenon and its after-effect». China City Planning Review, 22 (2), 15-23.

Gu, C.; WANG, F.H. y LiU, G. (2005). «The structure of social space in Beijing in 1998: A socialist city in transition». Urban Geography [en línea], 26 (2), 167-192. <http://dx.doi.org/10.2747/0272-3638.26.2.167>

He, S.J.; Qian, J.X. y Wu, M.H. (2011). «Studentification in Urban Village: A case study of Xiadu village, Guangzhou». Geographical Research, 30 (8), 1508-1519. Edición original en chino.

Lian, S. (2009). Ant Tribe - Record about the village inhabited by graduates. Guilin: Guangxi Normal University Press. Edición original en chino.

- (2010a). «Ant Tribe: Problems, drawing and countermeasures». Chinese Academy of Social Code "Talent Blue Book (2010)». Beijing: Social Sciences Academic Press. Edición original en chino.

- (2010b). Ant Tribe : Who's Time. Beijing: CITIC Publishing House. Edición original en chino.

LiAng, Z.; Chen, Y.P. y Gu, Y. (2002). «Rural Industrialization and Internal Migration in China». Urban Studies [en línea], 39 (12), 2175-2187. Edición original en chino. <http://dx.doi.org/10.1080/0042098022000033926>

Liu, Y. y Wu, F. (2006). "The state institutional transition and the creation of new urban poverty in China». Social Policy and Administration [en línea], 40 (2), 121-137. <https://doi.org/10.1111/j.1467-9515.2006.00480.x>

Logan, J.R. (ed.) (2001). The New Chinese city: Globalization and market reform. Oxford: Blackwell Publishers.

MA, L.J.C. y XIANG, B. (1998). «Native place, migration and the emergence of peasant enclaves in Beijing». The China Quarterly, 155, 546-581.

National Bureau of Statistics of China (2012). China's Total Population and Structural Changes in 2011 [en línea]. <http://www.stats.gov.cn/english/pressrelease/201201/t20120120_72112.html> [Consulta: 19 enero 2017].

Sit, V.F.S. (2000). "A window on Beijing: The social geography of urban housing in a period of transition, 1985-1990». Third World Planning Review [en línea], 22 
(3), 237-259.

<http://dx.doi.org/10.3828/twpr.22.3.ew72k625894h3377>

Wong, D.F.K.; LI, C.Y. y Song, H.X. (2007). «Rural migrant workers in urban China: Living a marginalised life». International Journal of Social Welfare [en línea], 16 (1), 32-40.

<http://dx.doi.org/10.1111/j.1468-2397.2007.00475.x>

XIANG, B. (1999). "Zhejiang village in Beijing: Creating a visible non-state space through migration and marketized networks». En: Pieke, F.N. y Mallee, H. Internal and international migration: Chinese perspectives. Surrey: Curzon.

Yuan, Y.; Wu, F. y Xu, X. (2009). "Transformation of the Chinese urban spatial patterns of poverty and deprivation». Geographica Sinica, 64 (6), 753-763. Edición original en chino. 